\title{
Point-of-care uric acid testing is useful in routine clinical care of gout
}

\author{
Philip L. Riches ${ }^{*}$ (D), Kristen Sing and Kathryn Berg
}

Keywords: Gout, Point-of-care, Uric acid meter

Fabre et al. recently reported that the HumaSens ${ }^{\text {plus }}$ point-of-care uric acid (UA) meter performed well in comparison to venous UA in a cohort of 238 diabetic patient [1]. We have performed a service evaluation of the HumaSens $2.0^{\text {plus }}$ UA meter in patients seen in a specialist gout clinic for investigation or review. All patients attending the clinic from August 2017 onward were offered fingerprick testing with results compared to a venous sample analysed using an Abbott colorimetric uricase assay as part of standard care. Summary characteristics of the patients included in the study are given in Table 1 with complete data available in Additional file 1.

Similar to the results of Fabre et al., we observed a close correlation between the capillary and venous UA levels (Fig. 1). We observed discrepancies which would influence treatment escalation decisions in just five individuals who had levels of UA close to the 0.3 $\mathrm{mmol} / \mathrm{l}$ threshold and seven individuals around the $0.36 \mathrm{mmol} / \mathrm{l}$ threshold. The performance of capillary uric acid measurements in identifying hyperuricaemic individuals was analysed using ROC curve analysis with an AUC of $99 \%$ for detection of venous UA levels above $0.3 \mathrm{mmol} / \mathrm{l}$ (Fig. 2a) and an AUC of 98.5\% for detection of venous UA levels above 0.36 mmol/l (Fig. 2b). These results compare favourably with those reported by Fabre et al. and possibly reflect improved performance of the HumaSens $2.0^{\text {plus }}$ device over the earlier HumaSens ${ }^{\text {plus }}$ device. We also evaluated the role of haematocrit as this was the only potential confounder identified by Fabre et al. Although haematocrit was associated with capillary UA levels independently of venous UA levels in our population, the addition of haematocrit to a prediction model of venous UA levels yielded a trivial increase in performance (ROC curve analysis AUC 99.2\% for UA levels greater than $0.3 \mathrm{mmol} / \mathrm{l}$, and unchanged AUC $98.5 \%$ at the threshold of $0.36 \mathrm{mmol} / \mathrm{l}$ ). On four occasions, 'Lo' error reading was obtained prompting immediate retesting. Three continued to give a 'Lo' reading with all these confirmed on venous testing as being below the reference range of the meter $(0.18 \mathrm{mmol} / \mathrm{l})$. The remaining 'Lo' error reading corrected on repeat testing.

Our results confirm the findings of Fabre et al. and confirm the reliability of the HumaSens $2.0^{\text {plus }}$ point-of-care device in a population of gout patients. For the vast majority of patients, these results can reliably inform discussions around treatment compliance and the need for additional therapy, as well as allowing direct prescriptions of additional treatment without the need to recall patients.

Table 1 Characteristics of study population $(n=131)$

\begin{tabular}{ll}
\hline Characteristic & Value \\
\hline Gout & $124(94.6 \%)$ \\
Visible tophi & $41(31.3 \%)$ \\
Age (years) & $58.1( \pm 16.2)$ \\
Male sex & $110(84.0 \%)$ \\
Weight (kg) & $91.9( \pm 21.7)$ \\
Alcohol (u/week) & $9.7( \pm 13.2)$ \\
Diuretics & $25(19.1 \%)$ \\
Anti-hypertensive medication & $44(33.6 \%)$ \\
Urate lowering therapy & $98(74.8 \%)$ \\
Renal impairment & eGFR $<30 \mathrm{ml} / \mathrm{min} / 1.73 \mathrm{~m}^{2} 2(9.1 \%)$ \\
& eGFR 30-60 ml/min/1.73m² $23(17.5 \%)$ \\
\hline
\end{tabular}

* Correspondence: priches@staffmail.ed.ac.uk

Institute of Genetics and Molecular Medicine, University of Edinburgh, Edinburgh EH4 2XU, UK

(c) The Author(s). 2019 Open Access This article is distributed under the terms of the Creative Commons Attribution 4.0 International License (http://creativecommons.org/licenses/by/4.0/), which permits unrestricted use, distribution, and

reproduction in any medium, provided you give appropriate credit to the original author(s) and the source, provide a link to the Creative Commons license, and indicate if changes were made. The Creative Commons Public Domain Dedication waiver (http://creativecommons.org/publicdomain/zero/1.0/) applies to the data made available in this article, unless otherwise stated. 


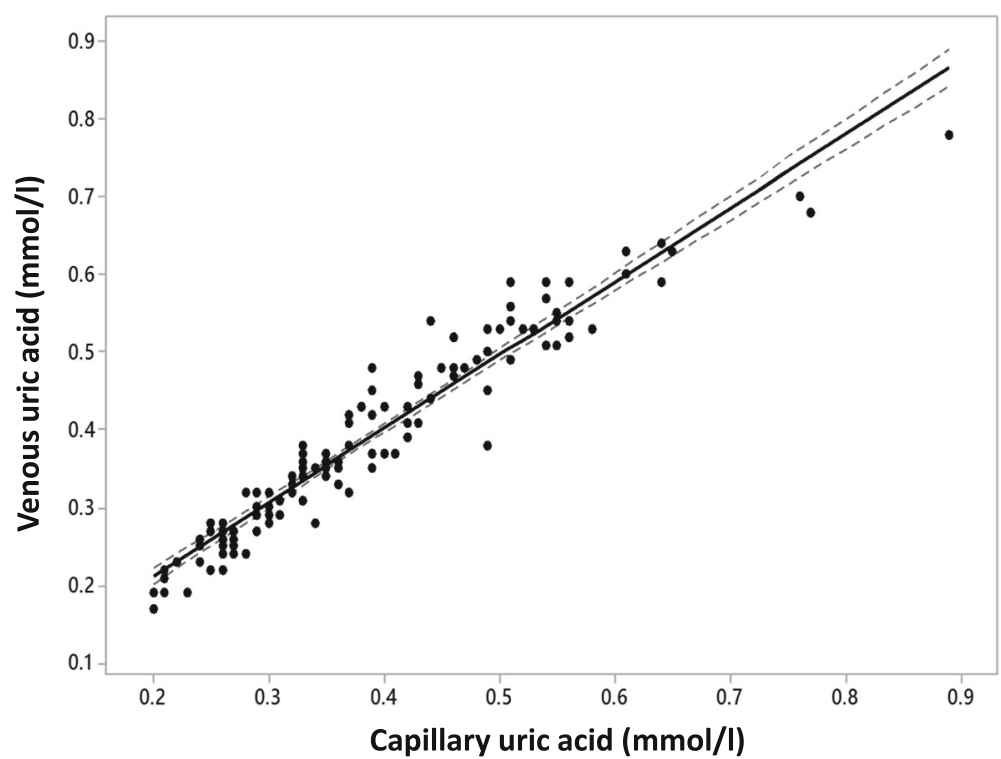

Fig. 1 Correlation between capillary and venous uric acid measures. Regression line with 95\% confidence intervals is shown. Pearson correlation coefficient $96.4 \%(p<0.001)$

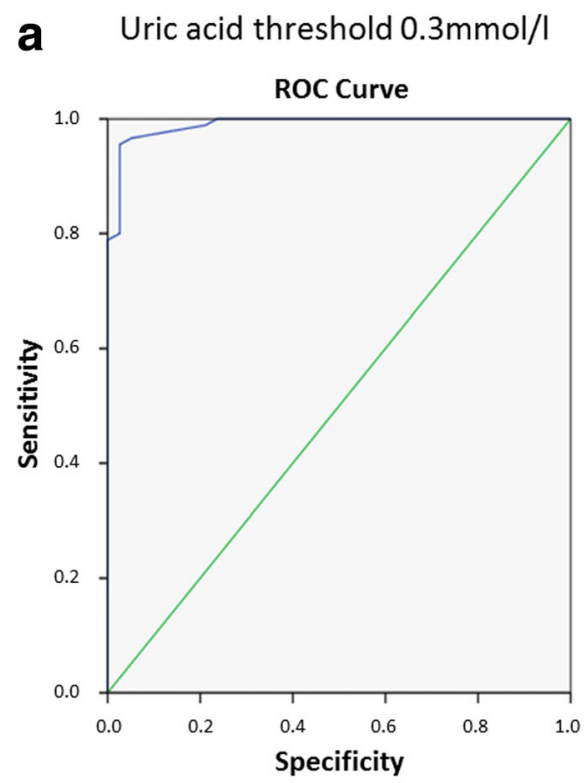

b Uric acid threshold $0.36 \mathrm{mmol} / \mathrm{l}$

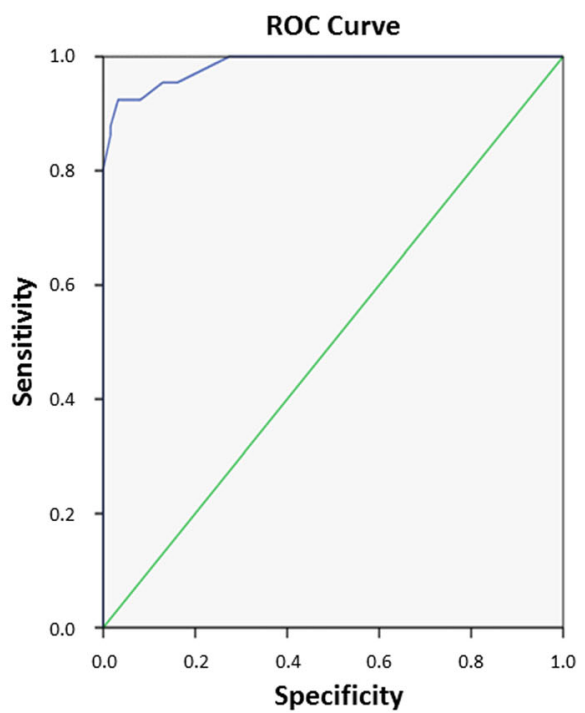

Fig. 2 ROC curve analysis of fingerprick uric acid (UA) measurements in identifying individuals with hyperuricaemia defined as venous $U A$ greater than $0.3 \mathrm{mmol} / \mathrm{I}$ (a, AUC 99\%) or greater than $0.36 \mathrm{mmol} / \mathrm{l}$ (b, AUC 98.5\%). Use of a fingerprick threshold of $0.3 \mathrm{mmol} / \mathrm{l}$ results in $97.8 \%$ sensitivity and $86.8 \%$ specificity for venous readings above this same level (within this cohort $100 \%$ sensitivity was given by a capillary threshold of 0.28 $\mathrm{mmol} / \mathrm{l}$ and $100 \%$ specificity by a capillary threshold of $0.35 \mathrm{mmol} / \mathrm{l})$. Similarly, fingerprick readings at the $0.36 \mathrm{mmol} / \mathrm{l}$ threshold yielded $92.4 \%$ sensitivity and $91.9 \%$ specificity (with $100 \%$ sensitivity seen at a threshold of $0.33 \mathrm{mmol} / \mathrm{l}$ and $100 \%$ specificity at $0.4 \mathrm{mmol} / \mathrm{l}$ ) 


\section{Additional file}

Additional file 1: Raw data from gout clinic cohort. (XLSX 27 kb)

Abbreviation

UA: Uric acid

\section{Acknowledgements}

We thank the Lothian gout patient advisory group for testing the uric acid meters used and Prof Ralston for the review of the manuscript.

\section{Funding}

Uric acid meters were purchased from an unrestricted educational grant received from A. Menarini pharma UK in 2011.

Availability of data and materials

Raw data is available as Additional file 1.

\section{Authors' contributions}

PLR conceived and implemented the study and wrote the paper. AM and KB carried out the data extraction and reviewed the paper. All authors read and approved the final manuscript.

\section{Ethics approval and consent to participate}

Approval for this study was given by NHS Lothian research office.

\section{Consent for publication}

Not applicable.

\section{Competing interests}

The authors declare that they have no competing interests.

\section{Publisher's Note}

Springer Nature remains neutral with regard to jurisdictional claims in published maps and institutional affiliations.

Published online: 09 May 2019

\section{Reference}

1. Fabre S, Clerson P, Launay J-M, Gautier J-F, Tiphaine V-T, Riveline J-P, Platt A, Abrahamsson A, Miner JN, Hughes G, Richette P, Bardin T. Accuracy of the HumaSens ${ }^{\text {plus }}$ point of care uric acid meter using capillary blood obtained by fingertip puncture. Arthritis Res Ther. 2018;20:78-86. 